\title{
Internet of Things-Based Steam Pump Motor Protection Due to Voltage Unbalance
}

\author{
Bagas Aji Saputra ${ }^{1}$, Edy Prasetyo Hidayat $^{2}$, Afif Zuhri Arfianto ${ }^{3}$ \\ ${ }^{1,2}$ Program Studi Teknik Kelistrikan Kapal, Politeknik Perkapalan Negeri Surabaya \\ ${ }^{3}$ Program Studi Teknik Otomasi, Politeknik Perkapalan Negeri Surabaya \\ afifzuhri@ieee.org
}

\begin{abstract}
PLTGU is a gas and steam power plant, producing electrical energy of $3 \times 526$ MW. The PLTGU generation process has several supporting components, one of which is a three-phase induction motor. It requires a balanced three-phase supply voltage in its operation. The problem that frequently occurs is an unbalanced voltage supply, causing an imbalance of current going to the motor stator, if not directly corrected. It causes a high temperature on the motor, possibly to cause a fire. Based on the problems, a system for monitoring the protection of steam pump motorcycles due to voltage unbalance based on the Internet of Things is designed. It used a 1-phase AC Adapter voltage sensor, a current sensor SCT-013, an Arduino Uno as the processor, and web to display the system. The test results showed that the sensor could work well. It could read voltage with an error percentage not exceeding $1 \%$. The percentage error of the current sensor SCT- 013 was $5.15 \%$, but the value difference between the sensor and the Avo meter was 0.01. The system was displayed on the web to make to monitor the motor condition more easily.
\end{abstract}

Keywords-1 Phase AC Adapter, IoT, 3 phase Induction Motor, Monitoring system, SCT-013, Voltage Unbalance.

\section{INTRODUCTION}

PLTGU is a gas and steam power plant [1], a combination of a gas turbine and a steam turbine [2], [3], where the exhausted gas to rotate a turbine is reused to heat water to be dry steam in HRSG. Then, the steam resulted from the heating is used to rotate a steam turbine (PLTU) or called the Combine cycle. The unit generates electrical energy of $3 \times 526$ MW, so this type of power plant is designed to produce large and more efficient electric power.

The generation process has several components including a three-phase induction motor. The three-phase induction motor is used to convert electrical energy into motion energy to move a load in the electricity generation process. A motor in the generation process is used as a pump to pump wet steam from Dearator into Superheater [4]. The dry steam generated is then channeled to pump turbines. When one of the motor phases is decreasing, it affects the performance of the motor [5]. Voltage unbalance [6] disorder appears unexpectedly and greatly interferes with the process of electricity generation. It causes an imbalance of current that goes to the motor stator and leads to high temperatures [7][10] on the motor because the current that flows is very large and can burn the three-phase induction.
Based on the problems, it is necessary to design a monitoring system of a steam pump motor due to the unbalance of the voltage based on the Internet of Things (IoT) [11], [12]. The IoT monitoring system [13]-[15] acts as a device to remotely control the motor with an internet connection so that when it is necessary to check the voltage and the current on the motor, there is no need to come to the plant.

The IoT monitoring system operates by reading the data from the voltage sensor and current sensor using the Ethernet Shield [16], and then transmits them to the webserver, so users only need to access the webserver to track the motor state. The webserver provides voltage and current information on the motor. When one of the phases' voltage drops, the system works to turn off the motor automatically so that the generator does not get harm, and it gives a warning that shows a fault on the motor. A program shortens contact or mission delivery to allow faster and more accurate management of disruptions.

The research aims to design a monitoring system with SCT-013 current sensor input, AC Adapter voltage sensor, using an Internet Shield based on the Ethernet Shield to protect the motor using current sensor SCT-013, AC Adapter voltage sensor, and an Ethernet Shield module. It supposes to provide benefits, facilitate and accelerate the process of problem identification and communication to workers as appropriate, increase speed in handling disturbances to critical components in the generation process, adding insight into how to monitor unbalance of voltage and current in the motor. The system only processes data sent automatically to a web server using an Ethernet shield to be monitored from an infinite distance as long as there is an internet network.

\section{LITERATURE REVIEW}

\section{a. Ethernet Shield}

Ethernet Shield is a supporting device that functions to connect Arduino Uno [14], [17]-[20] into the internet network. It uses the WIZnet W5100 Ethernet Shield Chip, which has four simultaneous socket connections to access the Arduino Uno online [21] to write sketches. A USB cable connects the Arduino Uno program to a computer while a Cat5 UTP cable connects the Ethernet Shield to the router. The Arduino Uno Ethernet Shield specification [22] is an Arduino Uno micro-control board, a $5 \mathrm{~V}$ operation voltage on 
the Arduino Uno board, an Ethernet controller W5100 with internal buffer16K, a connection speed of 10/100 Mb, and SPI Ports. Figure 1 displays the Ethernet Shield with Arduino Uno.

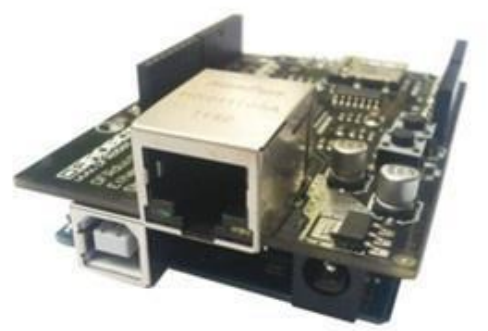

Fig. 1. Ethernet Shield with Arduino Uno

\section{b. Arduino Uno}

An Arduino Uno is a single-board microcontroller board type, an open-source Arduino Uno production based on ATmega328. The Arduino Uno has 14 digital input/output pins, six analog inputs, a $16 \mathrm{MHz}$ Crystal oscillator, a USB connection, a power supplies, an ICSP header, and reset buttons. Figure 2 illustrates the Arduino Uno. The detailed specifications of the Arduino Uno microcontroller board [23] are presented in Table 1.

TABLE I. SPECIFICATIONS ARDUINO UNO

\begin{tabular}{|c|c|}
\hline Parameter & Spesifikation \\
\hline Microcontroller & ATmega328P \\
\hline Operating Voltage & $5 \mathrm{~V}$ \\
\hline $\begin{array}{c}\text { InputVoltage } \\
\text { (recommended) }\end{array}$ & $7-12 \mathrm{~V}$ \\
\hline $\begin{array}{c}\text { Input Voltage } \\
\text { (limit) }\end{array}$ & $6-20 \mathrm{~V}$ \\
\hline Digital I/O Pins & $\begin{array}{c}14 \text { (of which } 6 \\
\text { provide PWM } \\
\text { output) }\end{array}$ \\
\hline $\begin{array}{l}\text { PWM Digital I/O } \\
\text { Pins } \\
\end{array}$ & 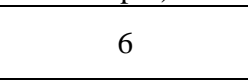 \\
\hline Analog Input Pins & 6 \\
\hline $\begin{array}{c}\text { DC Current per I/O } \\
\text { Pin }\end{array}$ & $20 \mathrm{~mA}$ \\
\hline $\begin{array}{c}\text { DC Current for } \\
\text { 3.3V Pin }\end{array}$ & $50 \mathrm{~mA}$ \\
\hline Flash Memory & $\begin{array}{c}32 \mathrm{~KB} \\
\text { (ATmega328P) } \\
\text { of which } 0.5 \mathrm{~KB} \\
\text { used by bootloader }\end{array}$ \\
\hline SRAM & $\begin{array}{c}2 \mathrm{~KB} \\
(\text { ATmega328P) }\end{array}$ \\
\hline EEPROM & $\begin{array}{c}1 \mathrm{~KB} \\
\text { (ATmega328P) }\end{array}$ \\
\hline Clock Speed & $16 \mathrm{MHz}$ \\
\hline
\end{tabular}

The functions of the Arduino Uno pin used to program Arduino Uno are [24]: 1). SPI (Serial Peripheral Interface) used to synchronize one or more devices quickly over short distances, 2). SCK (Serial Clock) to set Clock from master to slave, 3). MOSI (Master Out, Slave In) used in SPI in which the data is transferred from Master to Slave, 4). MISO
(Master in, Slave out) used in SPI in which the data is transferred from Slave to master, 5). A protocol 12 using a clock path (SCL) with (SDA) to exchange information, 6). $\mathrm{SC} 12$, the data path used by $\mathrm{I} 2 \mathrm{C}$ to identify that data is ready to be transferred, 7). SDA, the data path (bidirectional) used by I2C, 8). ICSP (In-Circuit Serial Programming) used to program a microcontroller, 9). VCC, namely the supply line voltage that is usually $+5 \mathrm{~V}, 10$ ). IOREF (Reference input/output) useful to protect the board from overvoltage, 11). Vin used to supply voltage from an external adapter, 12). GND (Ground Path), 13). USB used to transfer data from a computer to the board, 14). PWM (Pulse Width Modulation). marked with “ " support PWM signals, and 15). Analog Pin A0-A5, an Analog Pin, reading an analog value from 0-1023. The voltage supply is controlled, measured and decided using a voltage adapter sensor. It can assess the voltage level of either AC or DC. The input of this system is the voltage, while the output is the buttons, the analog voltage signal, the present signal, the noticeable signal, etc. Figure 3 displays an adapter voltage.

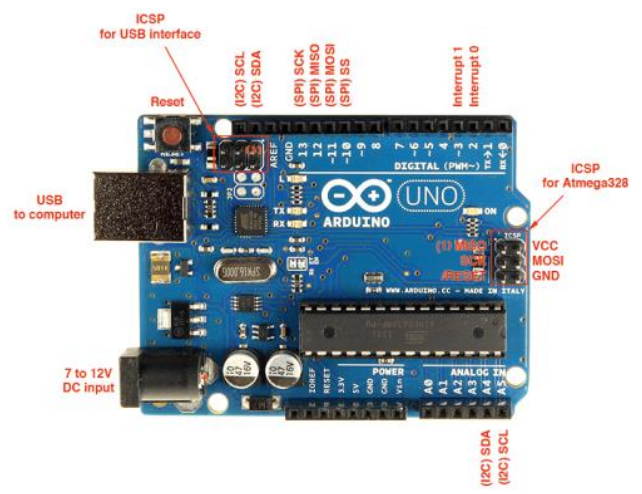

Fig. 2. Arduino Uno

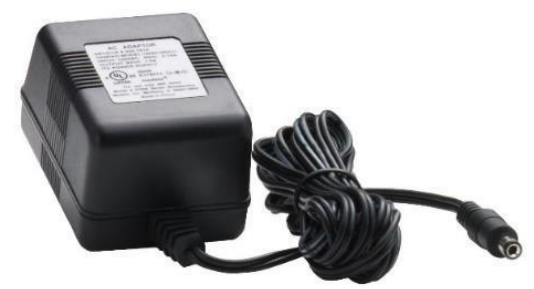

Fig. 3. Adapter voltage.

\section{c. Current Sensor SCT-013}

Current sensor SCT-013 is a Hall Effect Current sensor that can measure the amount of $\mathrm{AC}$ electric current. The current sensor was used as an AC meter on the electrical load. Figure 4 illustrates the current sensor SCT-013

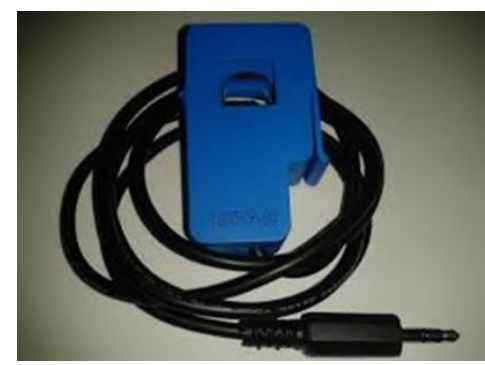

Fig. 4. Current sensor SCT-013 
Table 2 presents the specifications of the current sensor SCT-013 taken from the sensor datasheet [25]:

TABLE II. THE SPECIFICATIONS OF THE CURRENT SENSOR SCT-013

\begin{tabular}{|c|c|c|}
\hline No. & Pin & Function \\
\hline 1. & Max Current & $0-100 \mathrm{~A}$ \\
\hline 2. & Temperature & $-25^{\circ} \mathrm{C}-70^{\circ} \mathrm{C}$ \\
\hline 3. & Output & $0-50 \mathrm{~mA}$ \\
\hline
\end{tabular}

\section{d. Relay}

Daniel Relay is a switch that is controlled by the current. The relay has a low voltage coil wrapped around a core [26]. It has an iron armature that when flown by the current, it will be attracted to the core so that the contact path will change from normally open to normally closed contact. Figure 5 illustrates a relay.

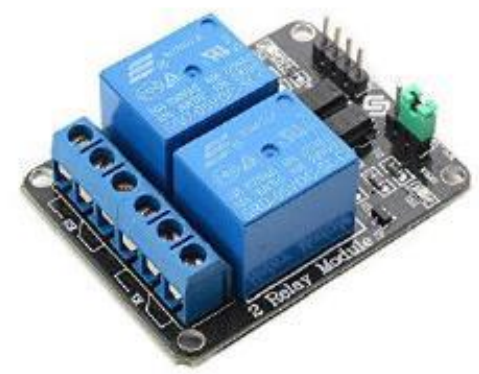

Fig. 5. Relay

\section{e. Three-phase motor}

A three-phase electric motor is the type of motor that is most widely used both in large and small industries because it has advantages both in terms of technical and economic. The system is very simple and can be used for all types of three-phase electric motors. The initial current when the electric motor works is greater, but it can be overcome by several starting systems. In general, a three-phase electric motor consists of rotors and stators. The rotor is the moving part, while the stator is the stationary part. There is a very low air gap between the stator and the rotor. Three-Phase Motor is illustrated in Figure 6.

Induction motors widely used in the industry have several advantages. The shape is simple and has a strong construction, and it rarely suffered significant damage. The prices are relatively cheap and reliable. It has high efficiency in normal turning conditions. It does not require a brush so that the power losses resulting from friction can be reduced, and it does not require special additional starting time and synchronization.

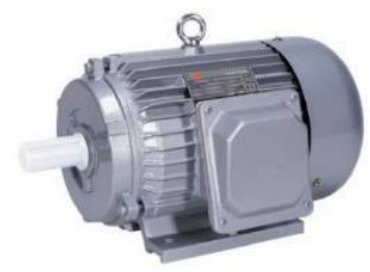

Fig. 6. Three-Phase Motor

\section{f. Voltage imbalance}

Voltage imbalance is a phenomenon observed in almost all countries adopting a three-phase system. Although the voltage generated by the generator has a balanced value, the effect of unbalanced loading during distribution can cause the voltage reaching the load unbalanced. There are many conditions of voltage imbalance occurring with the same VUF (Voltage Unbalance Factor) [27]. 1Ø - (Single Phase Under Voltage Unbalance is the condition when one phase of a three-phase system has a lower voltage compared to the nominal voltage. $2 \varnothing$ - (Two Phases Under Voltage Unbalance) is the voltage condition of two of the three phases is lower than the nominal voltage value. $3 \varnothing$ - (Three Phases Under Voltage Unbalance) is the voltage condition of the three channels of the three-phase system is unbalanced and is lower than the nominal value. $1 \varnothing$ - O (Single Phase Over Voltage Unbalance) is a condition where the voltage of one of the three phases is higher than the nominal voltage value. $2 \varnothing$ - O (Two Phases Over Voltage Unbalance) is the voltage condition of two of the three phases is higher than the nominal voltage.

\section{RESEARCH METHODS}

Designing a monitoring program for the steam pump motor protection due to voltage unbalance based on IoT requires a flow chart to simplify system development. Figure 7 illustrates the system flow diagram. From the picture, it can be seen that the AC adapter sensor 1 and the current sensor are read by Arduino. Then the data from Arduino is displayed on the webserver.

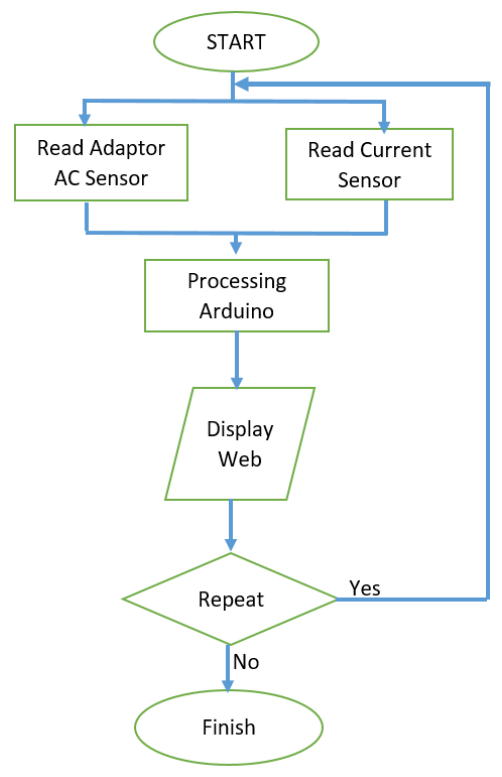

Fig. 7. system flow diagram

\section{a. Tool System}

The system design involved the design of the steam pump motor protection monitoring using SCT-013 current sensors, an AC Adapter voltage sensor, and a Wi-Fi Ethernet Shield module. Figure 8 shows the tool system diagram of the remote pump motor protection monitoring system. From the picture, it can be seen that the system uses a current sensor and a voltage sensor to read the current and motor voltage values. Data from Arduino is displayed on the webserver. 


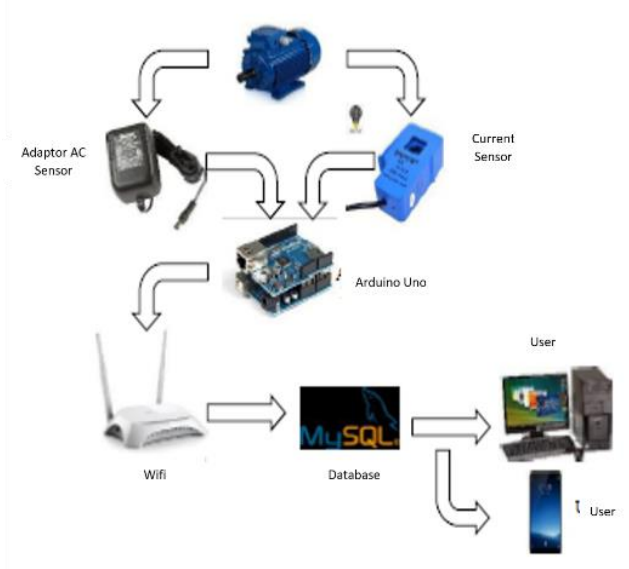

Fig. 8. Tool System Diagram

\section{b. Programming}

Figure 9 shows making a voltage and current monitoring program. From the picture, it can be seen that an emonlib library is needed to read data from current and voltage sensors. The data is then sent to the webserver.

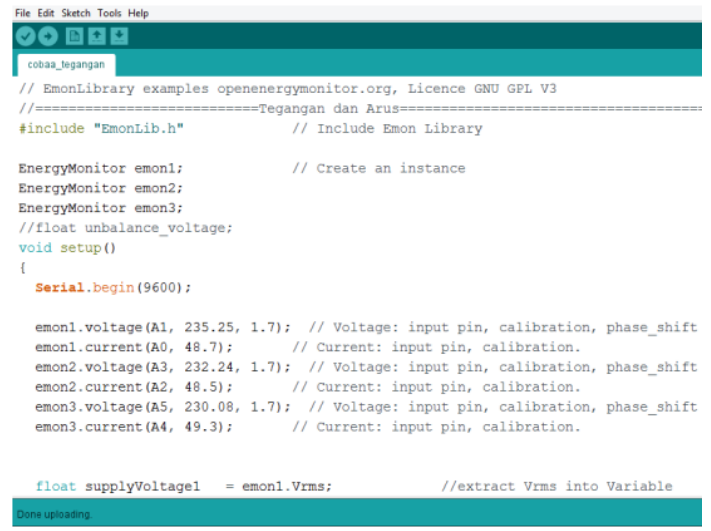

Fig. 9. A short program of voltage and current monitoring

\section{c. Creating a MySQL database}

Figure 10 shows creating a MySQL database. From the figure, it appears that there are two tables in the database. The two tables consist of a record table and a user table

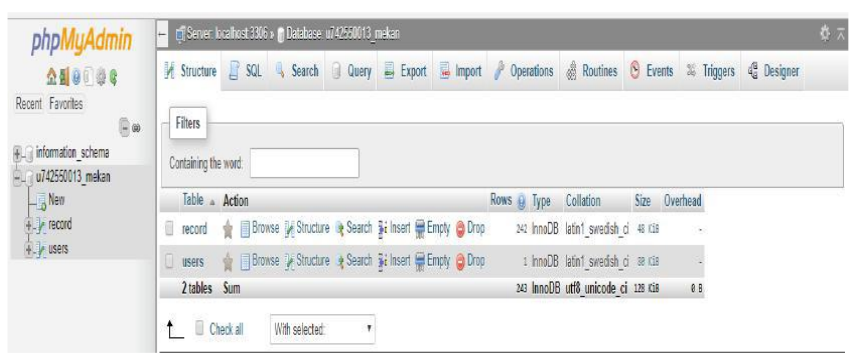

Fig. 10. Database display

\section{d. Making a web to display data}

Figure 11 shows making a web to display data. From the picture, it can be seen that the voltage and current from the microcontroller are displayed on the webserver.

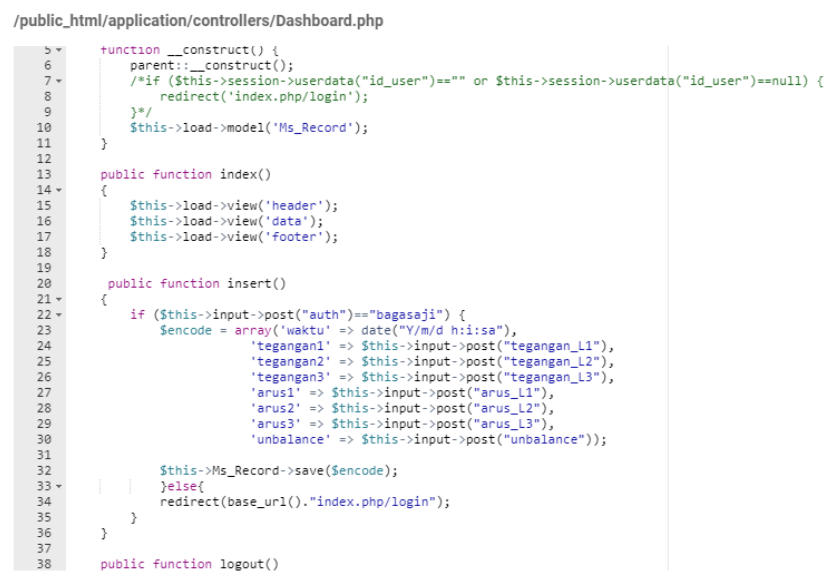

Fig. 11. Code for displaying data to the web

\section{e. Design}

The design is used to facilitate prototype framework manufacturing. It used the 2017 Sketch-up application. Figure 12 displays a prototype design of a tank monitoring system with a description of the figure shown in Table 3.

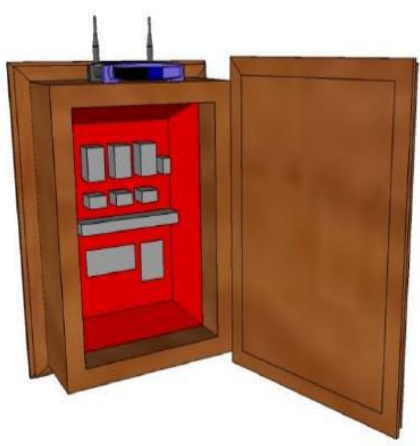

Fig. 12. Design and Construction

TABLE III. Descriptions of design for Single Line Panel

\begin{tabular}{|l|l|}
\hline No & Caption \\
\hline 1. & MR3420 TP-Link Router \\
\hline 2. & DC Relay \\
\hline 3. & Phase 1 AC Adapter Voltage Sensor \\
\hline 4. & Motor dimmer \\
\hline 5. & Voltage divider circuit \\
\hline 6. & Ethernet Shield and Arduino Uno Modules \\
\hline 7. & Current Sensor SCT-013 \\
\hline
\end{tabular}

\section{f. Panel installation}

Panel installation is used as a control for three-phase motors and simulations when unbalance occurs. When working normally, the green indicator light is on. When the voltage drops, it activates a buzzer that indicates interference in the motor. Figure 13 illustrates a single line circuit in the design. 


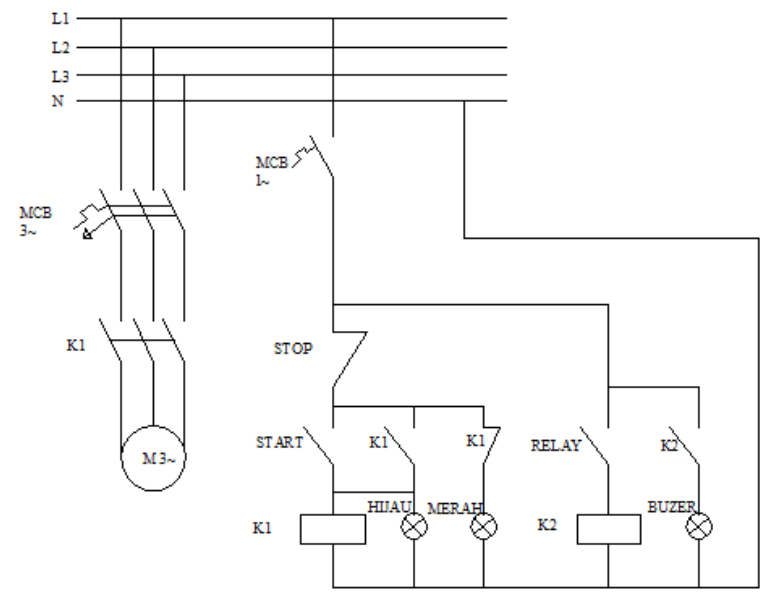

Fig. 13. Single Line.

\section{RESUlT AND DISCUSSION}

\section{a. Input Component Test}

The input component test was carried out to ensure that all inputs had worked well by giving a program to each component used as the input. The test was successful if the component run according to its working principle. The monitoring system used two inputs, consisting of three sensors of 1-phase AC adapter as the voltage sensor and three SCT-013 current sensors [28].

\section{b. Prototype Test}

After the design has been made, the next step was to test whether the design was running or not. The test was done by comparing the results of the serial print and web pages, whether they can be sent or not. It was carried out three times by displaying five data in the serial print with those on the web page [29] [30].

\section{c. First Test}

The first test was carried out to ascertain whether the program and series were running well or not. When the sensor results were the same as the values displayed on the web page, it meant the system had worked well. The sensor was very influential for data stored on the database. Figure 14 illustrates the monitor display series.

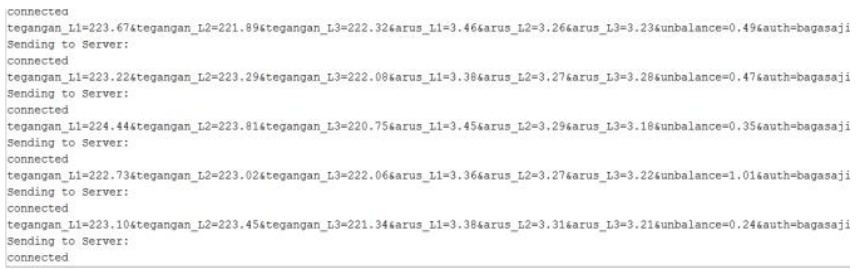

Fig. 14. Monitor Display Series

The test results presented in Table 4 show the value of the sensor sent via Arduino to the database, and it also described the five data on the web page sent from the sensor readings. The prototype worked well when voltage unbalances occurred.

\section{d. Second Test}

The data were sent completely by Arduino Uno microcontroller to the web seen on the serial monitor and directly connected to the server to store the data directly into the database. The web page read and displayed the data sent by Arduino and stored them in the database. The second test was performed according to what was commanded by the program. Figure 15 shows the database under normal circumstances

TABLE IV. READINGS ON THE MONITOR SERIES

\begin{tabular}{|c|c|c|c|c|c|c|c|c|}
\hline \multirow{2}{*}{ No } & \multicolumn{5}{|c|}{ Sensor Value } & \multirow{2}{*}{ Unbalance } & \multirow{2}{*}{ Status } \\
\cline { 2 - 6 } & \multicolumn{3}{|c|}{ Voltage } & \multicolumn{3}{|c|}{ Ampere } & \\
\cline { 2 - 6 } & L1 & L2 & L3 & L1 & L2 & L3 & & Send \\
\hline 1 & $\begin{array}{c}223, \\
10\end{array}$ & $\begin{array}{c}223, \\
45\end{array}$ & $\begin{array}{c}221, \\
34\end{array}$ & 3,38 & 3,31 & 3,21 & 0,24 & Send \\
\hline 2 & $\begin{array}{c}222, \\
73\end{array}$ & $\begin{array}{c}223, \\
02\end{array}$ & $\begin{array}{c}222, \\
06\end{array}$ & 3,36 & 3,27 & 3,22 & 1,01 & Send \\
\hline 3 & $\begin{array}{c}224, \\
44\end{array}$ & $\begin{array}{c}223, \\
81\end{array}$ & $\begin{array}{c}220, \\
75\end{array}$ & 3,45 & 3,29 & 3,18 & 0,35 & Send \\
\hline 4 & $\begin{array}{c}223, \\
22\end{array}$ & $\begin{array}{c}223, \\
29\end{array}$ & $\begin{array}{c}222, \\
08\end{array}$ & 3,38 & 3,27 & 3,28 & 0,42 & Send \\
\hline 5 & $\begin{array}{c}223, \\
67\end{array}$ & $\begin{array}{c}221, \\
89\end{array}$ & $\begin{array}{c}222, \\
32\end{array}$ & 3,46 & 3,26 & 3,23 & 0,48 & \\
\hline
\end{tabular}

\begin{tabular}{|c|c|c|c|c|c|c|c|}
\hline $2018-07-2510093: 38$ & 22689 & 233.62 & 223.32 & 348 & 3.44 & 3.91 & 07 \\
\hline $2010-07-2510.98 .393$ & 22575 & 223.62 & 223.18 & 349 & 3.5 & 3.31 & 0.73 \\
\hline $2010-07-2510-2325$ & 225.9 & 2334 & 223.41 & 3.5 & 3.35 & 3.31 & 0.58 \\
\hline $2018-07-2510.23 .18$ & 225.70 & 224.43 & 223.18 & 3.5 & 3.38 & 328 & 0.99 \\
\hline $2018-07-251002: 05$ & 223.5 & 223.0 & 282.34 & 3.51 & 3.44 & 317 & 0.68 \\
\hline $2018-07-251002559$ & 22595 & 22.37 & 2239 & 3.51 & 3.5 & 329 & 072 \\
\hline
\end{tabular}

Fig. 15. Database under normal circumstances.

\section{e. Tool Work Procedure}

The working procedure aimed to clarify the working process of the tool to minimize errors in operating the system. The SOP for the monitoring design was: 1) installing the voltage sensor in the L1, L2, and L3 to monitor the voltage on the motor, 2) installing the current sensor in the L1, L2, and L3 phases to monitor the current in the motor, 3) connecting the three-phase voltage source, 4) connecting the power supply with the voltage and pressing the switch to turn on the system, 5) pressing the reset button on the ethernet shield to connect the Arduino to the internet network, 6) opening the web page to see the voltage and current conditions on the motor, 7) login into the web page to open the data page to view the records stored in the database, and 8 ) opening the graph page to see the comparison between L1, L2, and L3 voltages.

\section{CONCLUSION}

The readings of the 1-phase AC Adapter voltage sensor per phase voltage gauge, taken from three experiments with different voltages and ten times sensor tests, reveals that the sensor can display the voltage properly. The error percentage of $\mathrm{L} 1$ is $0.38 \%$, L2 is $0.10 \%$, and L3 is $0.30 \%$ measured using an Avo Meter measuring tool. The readings of the current sensor SCT-013 as a per-phase current gauge, taken from three experiments and ten times sensor tests with different current loads, show that the sensor can read the current satisfactorily. The error percentage $\mathrm{f}$ the $\mathrm{L} 1$ current is $0.78 \%$, L2 current is $0.29 \%$, and L3 current is $0.24 \%$ with the three- 
phase motor load, measured using Avo Meter. The 1-Phase AC adapter voltage sensor and the SCT-013 current sensor can send the data from sensor readings every 1 second. The web page has worked properly, displaying the sensor data in real-time every five seconds. The tool enables users to monitor the steam pump motor anywhere and anytime and to take the motor data much more quickly and analyze if the voltage unbalance occurred.

\section{REFERENCES}

[1] Z. Muhammad, Z. M. Yusoff, M. H. F. Rahiman, and M. N. Taib, "Steam temperature control for steam distillation pot using model predictive control," in 2012 IEEE 8th International Colloquium on Signal Processing and its Applications, 2012, pp. 474-479.

[2] H. Hosseini, A. Boudaghi, A. Mehri, S. F. Torabi, and H. Farshbar, "Mitigating SSR in Hybrid System with Steam and Wind Turbine by UPFC," in 2012 Proceedings of 17th Conference on Electrical Power Distribution, 2012, pp. 1-6.

[3] H. Yang, S. Chang, and R. Wu, "Analysis of the Sliding Pressure Operation for Throttle Controlled Steam Turbine Generation Unit," in 2012 Asia-Pacific Power and Energy Engineering Conference, 2012, no. 1, pp. 1-4.

[4] C. Xiaobo, C. Yuting, L. Jianhong, Q. Wenwei, and D. Chengjian, "A block receding horizon control of reheated steam temperature system based on multi-objective optimization," in 2012 Power Engineering and Automation Conference, 2012, pp. 1-5.

[5] M. Yilmaz and N. R. Dhansri, "A Smart Grid Intelligent Control Framework," in 2012 IEEE Green Technologies Conference, 2012, pp. $1-3$.

[6] A. Pietsch, G. Lynch, S. B. Sutherland, and T. W. G. Iii, "Enabling high-density energy storage: Design characteristics of Thermal Matrix Energy Storage and a highly conductive gas mixture," in 2012 International Conference on Smart Grid (SGE), 2012, pp. 1-8.

[7] J. Prinyakupt and T. Yootho, "Multichannel Temperature Monitor on IoT," 2016 9th Biomed. Eng. Int. Conf., pp. 1-4, 20160.

[8] P. Roy, J. Saha, N. Dutta, and S. Chandra, "Microcontroller based automated room light and fan controller," in 2018 Emerging Trends in Electronic Devices and Computational Techniques (EDCT), 2018, pp. $1-4$.

[9] D. Chen et al., "Design of Temperature Intelligent Control System based on Transcranial Micro Current Depression Therapeutic Instrument," in 2018 IEEE International Conference on Mechatronics and Automation (ICMA), 2018, pp. 1345-1349.

[10] Y. Sanjaya, A. Fauzi, D. Edikresnha, M. M. Munir, and Khairurrijal, "Air temperature regulation in a chamber for rotary forcespinning," in 2016 International Seminar on Sensors, Instrumentation, Measurement and Metrology (ISSIMM), 2016, pp. 28-31.

[11] R. Jayswal, R. Gupta, and K. K. Gupta, "Patient health monitoring system based on Internet of Things," in 2017 Fourth International Conference on Image Information Processing (ICIIP), 2017, pp. 1-4.

[12] N. Pughazendi, R. Sathishkumar, S. Balaji, S. Sathyavenkateshwaren, S. S. Chander, and V. Surendar, "Heart attack and alcohol detection sensor monitoring in smart transportation system using Internet of Things," in 2017 International Conference on Energy, Communication, Data Analytics and Soft Computing (ICECDS), 2017, pp. 881-888.

[13] S. A. Kokalki, A. R. Mali, P. A. Mundada, and R. H. Sontakke, "Smart health band using IoT," in 2017 IEEE International Conference on Power, Control, Signals and Instrumentation Engineering (ICPCSI), 2017, pp. 1683-1687.

[14] M. A. Desima, P. Ramli, D. F. Ramdani, and S. Rahman, "Alarm system to detect the location of IOT-based public vehicle accidents," in 2017 International Conference on Computing, Engineering, and Design (ICCED), 2017, pp. 1-5.

[15] S. Coulter, M. Mostes, G. Lightbody, E. Popovici, and W. Fennell, "Low power IoT platform for vital signs monitoring," in 2017 28th Irish Signals and Systems Conference (ISSC), 2017, pp. 1-5.

[16] R. K. Kodali and K. S. Mahesh, "Smart emergency response system," in TENCON 2017 - 2017 IEEE Region 10 Conference, 2017, pp. 712717.

[17] M. N. Rajkumar, S. Abinaya, and V. V. Kumar, "Intelligent irrigation system - An IOT based approach," in 2017 International Conference on Innovations in Green Energy and Healthcare Technologies (IGEHT), 2017, pp. 1-5.

[18] P. N. Crisnapati, I. N. K. Wardana, I. K. A. A. Aryanto, and A. Hermawan, "Hommons: Hydroponic management and monitoring system for an IOT based NFT farm using web technology," in 2017 5th International Conference on Cyber and IT Service Management (CITSM), 2017, pp. 1-6.

[19] K. Sujatha, N. P. G. Bhavani, T. K. Reddy, and K. S. R. Kumar, "Internet of things for flame monitoring power station boilers," in 2017 Trends in Industrial Measurement and Automation (TIMA), 2017, pp. $1-7$.

[20] S. Sarkar, G. Ghosh, A. Mohanta, A. Ghosh, and S. Mitra, "Arduino based foot pressure sensitive smart safety system for industrial robots," in 2017 Second International Conference on Electrical, Computer and Communication Technologies (ICECCT), 2017, pp. 1-6.

[21] N. Pothirasan and M. P. Rajasekaran, "Automatic vehicle to vehicle communication and vehicle to infrastructure communication using NRF24L01 module," 2016 Int. Conf. Control Instrum. Commun. Comput. Technol. ICCICCT 2016, pp. 400-405, 2017.

[22] S. Silvirianti, A. S. R. Krisna, A. Rusdinar, S. Yuwono, and R. Nugraha, "Speed control system design using fuzzy-pid for load variation of automated guided vehicle (agv)," Proc. 2017 2nd Int. Conf. Front. Sensors Technol. ICFST 2017, vol. 2017-Janua, pp. 426-430, 2017.

[23] R. K. A. Sakir, A. Rusdinar, S. Yuwono, A. S. Wibowo, Silvirianti, and N. T. Jayanti, "Movement control algorithm of weighted automated guided vehicle using fuzzy inference system," 2017 2nd International Conference on Control and Robotics Engineering (ICCRE). IEEE, pp. 135-139, Apr-2017.

[24] P. Ghosh, J. A. Tran, and B. Krishnamachari, "ARREST: A RSSI Based Approach for Mobile Sensing and Tracking of a Moving Object," 2017.

[25] V. Jaiganesh, J. Dhileep Kumar, and J. Girijadevi, "Automated guided vehicle with robotic logistics system," Procedia Eng., vol. 97, no. December, pp. 2011-2021, 2014.

[26] S. Barai, D. Biswas, and B. Sau, Estimate distance measurement using NodeMCU ESP8266 based on RSSI technique, vol. 2018-Janua. 2018.

[27] A. De Angelis et al., "Design and Characterization of a Portable Ultrasonic Indoor 3-D Positioning System," IEEE Trans. Instrum. Meas., vol. 64, no. 10, pp. 2616-2625, 2015.

[28] M. Stusek, J. Pokorny, P. Masek, J. Hajny, and J. Hosek, "A noninvasive electricity measurement within the smart grid landscape: Arduino-based visualization platform for IoT," in 2017 9th International Congress on Ultra Modern Telecommunications and Control Systems and Workshops (ICUMT), 2017, vol. 2017-Novem, pp. $423-429$.

[29] S. U. Abdi, K. Iqbal, and J. Ahmed, "Development of PC-based SCADA training system," in 2016 IEEE International Conference on Industrial Technology (ICIT), 2016, vol. 2016-May, pp. 1192-1197.

[30] A. Khan, A. Al-Zahrani, S. Al-Harbi, S. Al-Nashri, and I. A. Khan, "Design of an IoT smart home system," in 2018 15th Learning and Technology Conference (L\&T), 2018, pp. 1-5. 